Chapman University

Chapman University Digital Commons

Communication Faculty Articles and Research

School of Communication

$11-30-2016$

\title{
"In Principle We Have Agreement, But in Practice It Is a Bit More Difficult": Obtaining Organizational Buy-In to Patient-Centered Medical Home Transformation
}

Janelle Applequist

Michelle Miller-Day

ChapmanUniversity, millerda@chapman.edu

Peter F. Cronholm

University of Pennsylvania

Robert Gabbay

Harvard Medical School

Deborah S. Bowen

Follow this and additional works at: http://digitalcommons.chapman.edu/comm_articles

Part of the Health and Medical Administration Commons, Health Services Administration Commons, $\underline{\text { Health Services Research Commons, and the Other Medicine and Health Sciences }}$ Commons

\section{Recommended Citation}

Applequist, J., Miller-Day, M., Cronholm, P. F., Gabbay, R. A., \& Bowen, D. S. (2016). “In Principle We Have Agreement, But in Practice It Is a Bit More Difficult” Obtaining Organizational Buy-In to Patient-Centered Medical Home Transformation. Qualitative Health Research, 1049732316680601. doi: 10.1177/1049732316680601 


\section{"In Principle We Have Agreement, But in Practice It Is a Bit More Difficult": Obtaining Organizational Buy-In to Patient-Centered Medical Home Transformation}

Comments

This is a pre-copy-editing, author-produced PDF of an article accepted for publication in Qualitative Health Research in 2016 following peer review. The definitive publisher-authenticated version is available online at DOI:10.1177/1049732316680601.

\section{Copyright}

The authors 
Obtaining PCMH Organizational Buy-In

Applequist, J., Miller-Day, M., Cronholm, P. F., Gabbay, R. A., \& Bowen, D. S. (2016). “In

Principle We Have Agreement, But in Practice It Is a Bit More Difficult” Obtaining

Organizational Buy-In to Patient-Centered Medical Home Transformation. Qualitative Health

Research, 1049732316680601.

\begin{abstract}
The patient-centered medical home (PCMH) is a model of care that emphasizes the coordination of patient treatment amongst health care providers. Practice transformation to this model, however, presents a number of challenges. One of these challenges is getting the buy-in of all personnel to commit to making organizational changes in the journey to becoming a nationally recognized medical home. This study investigated internal messages of buy-in as communicated by practices transitioning to this type of care. Grounding itself in stakeholder theory, this study analyzed interviews with staff, administration, and practitioners from 20 medical practices in a mid-Atlantic state. The analysis revealed three overarching themes: (1) communication amongst staff that is open, consistent; (2) implementation of reinforcement techniques; and (3) access to a change implementer who encourages successful evolution. Discussion of these themes provides recommendations for communication approaches to organizational buy-in for medical practices hoping to become a PCMH.
\end{abstract}

Keywords: behavior change; group interaction; health care; health care, managed; health care, teamwork

Current models of primary care tend to be fragmented and confusing for both patients and healthcare providers. The design of these models privileges the treatment of acute illness, meaning that preventive and consistent care over time by definition, receive less attention 
Obtaining PCMH Organizational Buy-In

(Elhauge, 2010). Many providers are now voluntarily moving away from these disorganized, individual-provider approaches to medical care; as a result, there is an emergence in the United States of network- and team-based models, helping to address the dynamics associated with patient needs and expectations (Kajamaa \& Hilli, 2014).

In response to high health care costs and poor health-related outcomes, health care managers and policy makers in the United States have been striving to better coordinate patients with their own particular health care systems. One such response is the implementation of the patient-centered medical home (PCMH), an enhanced primary-care model that relies upon patient outreach and team-based principles to improve the field of healthcare. The PCMH is a model for delivering enhanced primary care, and has been growing in popularity through dozens of pilot programs being tested nationwide (Berenson \& Horvath, 2003).

\section{The Patient-Centered Medical Home}

This model is a response to an increased need for team-based primary care (Grumbach \& Bodenheimer, 2004). The triple convergence of an aging U.S. population, an increase in adults with multiple chronic conditions, and the complexities associated with administering the highestquality health care in the most efficient way possible have substantiated the necessity of more team-based care initiatives (Crocker Houde, Devereaux Melillo, \& Holmes, 2012).

The patient-centered model can be conceptualized as a fundamental shift toward more focused changes in the personal health care delivery system. The American Academy of Pediatrics (AAP), American Academy of Family Physicians (AAFP), American College of Physicians (ACP), and American Osteopathic Association (AOA) together created an operational definition that emphasizes specific activities that ought to occur within the transformation: patient relationships with personal physicians; a physician-directed, yet team-based, medical 
Obtaining PCMH Organizational Buy-In

practice; whole-person patient orientation; coordinated and/or integrated care; quality and safety measures; enhanced access to care with new communication options; and payment reform (American Academy of Family Physicians, 2009).

This model supports a "home base" for patients and practitioners that functions as a central hub for patient information, primary care, and care coordination ( "Joint principles," 2007). The goal is to provide a site for collaborative care, with an emphasis on team effort by the staff, and a broader goal of improving the quality of healthcare in the United States (Zarbock, 2011).

Five pillars often associated with the medical home include: a patient-centered orientation that privileges individual needs, culture and values; comprehensive, team-based care; coordinated care across all elements of the health care system, allowing patients to be easily connected to medical and social resources in their community; easy access to care, including care available after hours through telephone and e-mail; and a systems-based approach to quality that emphasizes responding to patient experiences (Rittenhouse, Shortell, \& Fisher, 2009).

By taking part in this transformative process, a medical practice has the opportunity to enjoy a possible increase in patient satisfaction with care, even as it experiences a decrease in the costs associated with care (Wise, Alexander, Green, Cohen, \& Koster, 2011). There is considerable evidence that primary care clinicians who have made the transition to PCMH report increased satisfaction with their practice life (Epperly, 2011; Maeng, Graf, Davis, Tomcavage, \& Bloom Jr., 2011), with the model helping to reduce the use of the emergency departments and short/long-term hospital admissions (Reid, 2013). Through care coordination, patient engagement, and application of evidence-based care protocols, organizational transformation has led to a number of health care delivery improvements (Tai-Seale, et al., 2012). While the 
rewards are many, practitioners are becoming ever more aware that successful implementation is, simply stated, hard work (Korda \& Eldridge, 2011).

To promote the adoption of the previously mentioned elements of the PCMH, in 2007, the National Committee for Quality Assurance (NCQA) established a set of standards for practices to achieve PCMH status, divided into three levels of achievement, organized along nine areas, and involving 30 discrete elements, ten of which are mandatory (Kuzel \& Skoch, 2009). Level I recognition means five of the "must pass" elements need to be met; level II or III requires that all ten of the "must pass" elements be met.

Traditional models of health care rely on fee-for-service methods, which reward quantity of patients seen over quality of patient outcomes. The model attempts to re-align payment incentives by combining the traditional fee-for-service method with a three-part model that includes a monthly care coordination payment, a visit-based fee-for-service component, and a performance-based component (American College of Physicians, 2014). In order to receive government funding for PCMH implementation practices are required to become officially accredited according to the standards set forth by the NCQA.

The changes required to become an accredited PCMH tend to be organization-wide, transformative, developmental, and proactive. Implementing the model can prove to be timeconsuming, challenging, and expensive for medical practices.

At the heart of the model is an emphasis on patient-centered care, conceived as a practice-based approach encouraging the self-examination of organizational relationships and working practices (Liberati et al., 2015). The transformation requires more than just the financial components of its implementation; it demands “buy-in” from the key stakeholders. Stakeholders are defined in this manuscript as those individuals who can affect or be affected by 
the organization's actions, changes, or goals. In the case of medical practices, this chiefly includes medical providers and staff members who are responsible for all organizational changes in moving toward the model's adoption.

How this transformative process, its challenges, and its benefits are communicated amongst staff members becomes important for buying-in to core patient-centered principles and the need for change. Researchers have called for evidence-based studies to determine how to best harness the positive aspects of organizational change associated with health care providers (Hendy \& Barlow, 2012). Specifically, as Morden et al. (2015) point out, there is a need for theory-driven, qualitative investigations to understand more about complex interventions such as the PCMH, giving health care providers and case managers more insight into the context and dynamics of successful change settings.

Previous research has examined perceptions of particular providers (e.g. nurse leaders, nursing home residents), yet practice-wide analyses including a variety of the roles associated with health care delivery have yet to be considered alongside specific communicative recommendations for success (Garcia, Harrison, \& Goodwin, 2016; Salmela, Eriksson, \& Fagerström, 2013). Research has yet to examine model adoption and rollout through the lens of stakeholder theory, specifically investigating not only what makes health care professionals adopt a new change, but more importantly, what communicative techniques best ensure that these new behaviors will be adopted now and performed in the future.

\section{Buy-In}

The concept of buy-in is implicit in the terminology used to discuss organizational change in health care, and has been found to be particularly important in today's culture where patients rely upon a cohesive unit for their care (Applequist, 2013). Nutting and colleagues 
Obtaining PCMH Organizational Buy-In

(2010) argue that a "shared vision” is an essential ingredient in managing medical practice change. Garside (1998), in particular, implicitly argued for the importance of buy-in from organizational members when making recommendations for organizational change in health systems. Yet while this shared vision is repeatedly promoted, little information is available to guide organizational change leaders - such as those promoting transformation - in how to promote buy-in among personnel at all levels of the organization. Clearly, more information is needed regarding strategies for achieving buy-in among healthcare personnel.

Other qualitative studies have examined stakeholder perspectives on the PCMH, but these studies primarily analyze the communication between providers and their patients rather than focusing solely on the organization's transformation into a medical home (Aysola et al., 2015; Keeley et al., 2014). One study, for example, used qualitative methods that emphasized higher performing versus lower performing practices to determine levels of motivation and capability (Wise et al., 2011).

The specific challenges related to the organizational change process of the PCMH have been studied, but specific communicative techniques used by practices to prevent or overcome these barriers yields little information (Nutting et al., 2010; O’Malley et al., 2014; Tuepker et al., 2014). Furthermore, none of the aforementioned studies were guided by stakeholder theory. As discussed in more detail below, employing stakeholder theory as a guiding theoretical framework can focus an inquiry to the communication practices that serve to effectively manage relationships across an organization while implementing change.

In one of the few studies examining organizational buy-in and the patient-centered medical home, the results of Bleser et al. (2014) suggest that effectively communicating and internally campaigning for the change facilitates greater likelihood of practice buy-in. Simply 
Obtaining PCMH Organizational Buy-In

stated, the study found that all personnel within a medical practice should share the same goals and beliefs about the benefits of PCMH model adoption, and should understand the challenges inherent in organizational change.

The content of messages exchanged within an organization to facilitate change is important to understand in order to assess change outcomes, and Bleser et al. (2014) advised research to examine more specifically how these messages of collective effort are communicated amongst organization members to increase the likelihood of sustainable change. The current study is a response to this call, providing a field-based investigation of the messages used to promote organizational buy-in to change, and an examination of how those messages are conveyed in transitioning organizations.

\section{Theoretical Foundation}

The theoretical framework guiding the current study is Lewis’ organizational stakeholder model of change, situated within the context of stakeholder theory. Stakeholder theory considers cooperative activity in an organization while addressing moral- and value-driven goals used in trying to achieve strategic change (Freeman, 1984; Freeman, 2002; Freeman \& Philips, 2002; Phillips, Freeman, \& Wicks, 2003). Although stakeholder theory has been established in the academic community as a necessary lens for analyses of corporate structures, research investigating organizational change occurring in health care units is necessary, as ethical responsibilities, communication response styles, and reiteration of goals are present in both sectors (Elms, Berman, \& Wicks, 2002). Changes affecting the structure of health care delivery organizations merit analysis from the lens of stakeholder theory in particular because of its emphasis on ethical decision-making, a paramount component of practicing sound medicine. 
Obtaining PCMH Organizational Buy-In

Recognizing that stakeholders often have varying interests, this theory evaluates how strategic actions are decided upon and executed while simultaneously managing relationships across the organization (Freeman, 1984; Freeman, 2002; Freeman \& Philips, 2002; Lewis, 2011; Lewis \& Siebold, 1993). Current forms of health care delivery in the United States acknowledge the importance of patients, but also rely upon the stakeholders of the delivery system as well. Beyond the ethical, legal, and social obligations that overlap between stakeholder theory and health care, there is an economic incentive as well, with cost containment of health care being a goal of the United States. Additionally, a fundamental thesis of stakeholder theory is that organizations should be managed not only in the best interests of employees, but of all constituents - in this case, patients, reflecting a goal of socially responsible actions.

In a health care setting, for example, a registered nurse may be centrally focused on providing physical care to patients by obtaining vital signs, while the office manager's primary concern is keeping the infrastructure of the practice intact (billing, scheduling, etc.), meaning that there are different audiences in one organization who may see their role in an organization differently. According to stakeholder theory, messages about the need for organizational change will be adapted to these different stakeholder audiences (Lewis, 2011). Stakeholder theory looks at how organizations manage these competing interests, particularly during periods of organizational transition (Lewis \& Siebold, 1998). A central component of this theory is the amount of attention paid to those within an organization that can either assist or hinder successful implementation of change objectives (Freeman, 2002; Freeman \& Philips, 2002; Phillips, Freeman, \& Wicks, 2003; Stieb, 2009).

Three approaches to stakeholder theory exist. The descriptive approach looks at existing relationships among stakeholders. An instrumental approach tests assumptions concerning 
Obtaining PCMH Organizational Buy-In

specific actions and relationships (Jones \& Wicks, 1999; Lewis, 2011). Finally, the normative approach focuses on the ethical obligations an implementer has to its stakeholders. In the context of this research, the health care organization is viewed through its internal and external relationships, ultimately providing a descriptive approach to PCMH transformation.

Lewis’ organizational stakeholder model of change implementation (OSMCI) (see Figure 1), (Lewis, 2007) addresses the implementer’s strategies for affecting change amongst stakeholders. Thus, this theoretical framework is useful to guide the current study. Indeed, PCMH change literature often discusses the need for "change leaders," "champions," or "points of contact," which are all synonymous with “change implementer” (Kralewski, Zink, Dowd, \& Tong, 2016; Wise, Alexander, Green, Cohen, \& Koster, 2011).

First and foremost, the OSMCI promotes consideration of the perception of the main change implementer (or “champion”), along with key stakeholders, the organization’s history with change, readiness/willingness to change amongst staff, and perceptions of the need for greater efficiency. Based on these perceptions of change, along with considerations of other institutional factors, the implementer then creates his or her strategy for team-based change. Additionally, this model offers a-priori dimensions (not an exhaustive list) of communication strategies often used during organization change.

The OSMCI and stakeholder theory are applicable to the ever-changing structures of health care today, as it acknowledges various stakeholder perspectives in an effort to realize communicative strategies associated with greater change outcomes. Specifically, the model “posits that an implementer's recognition of stakeholders, identification of their relative stakes, and strategic adjustment to identified stakes and stakeholders are key predictors in accounting for outcomes of planned change implementation communication” (Lewis, 2007, p. 179). Through 
Obtaining PCMH Organizational Buy-In

successful communication strategies, the hope is that leaders and followers can create a greater bond and maintain a continued successful implementation of change.

One requirement for successful organizational change is open, or "better,” communication with group members (being facilitated by a change implementer). This particular requirement, however, remains vague in terms of proscriptions and prescriptions for what specific strategies to employ. Literature states that organizational change management should begin with a detailed diagnosis of the current situation in order to determine the need for and capability of change (Rothwell, Stavros, Sullivan, \& Sullivan, 2010). Therefore, this current study employs stakeholder theory as a guiding theoretical framework, with the OSMCI as a means of organizing observations, to examine how organizational change is being promoted within various medical practices striving to earn the national status of a patient-centered medical home. The overarching goal of this study is to describe the messages used to promote buy-in to organizational change in medical practices. In addition to describing these messages, we also seek to identify messages that organizational members report as most effective in securing their buy-in to organizational change. Guided by stakeholder theory and the OSMCI, we sought to answer the following research questions:

RQ1: What are the communicative strategies for obtaining organizational change buy-in among health care organizational members?

RQ2: Which communication strategies are perceived to be most effective?

\section{Method}

\section{Sample}


Obtaining PCMH Organizational Buy-In

Twenty medical practices from a mid-Atlantic state were included in this study. The practices were part of the first regional rollout of a statewide PCMH initiative in an effort to better understand the social processes associated with this rollout.

At the time of the study, all 20 practices were embarking on their process of PCMH recognition by the NCQA (Level I) and were in their second or third year of transformation moving toward level II or III recognition. To facilitate the process of change, six regional payers (comprised of health insurance companies, grants, and government subsidies) provided pro rata payments to all the practices to support care management implementation and practice transformation.

\section{Qualitative Interviews}

This study was part of a larger IRB-approved PCMH evaluation study. Individual interviews (with one interviewer and one note taker present) were conducted with clinicians $(n=$ 56), practice managers $(n=15)$, care managers $(n=13)$, and other staff $(n=52)$ in the 20 primary care medical practices, for a total of 136 interviews. Descriptions of the practices in terms of size, type, service area, and initial NCQA recognition level can be found in Bleser et al. (2012).

All participants were verbally instructed about informed consent by their interviewer. Participants were informed that researchers were seeking to gain a greater understanding of the organizational change process associated with rollout and all questions about the study were addressed at that time.

Interviews with consented participants were semi-structured, guided by an interview constructed to elicit information about each person's experience of organizational change during practice transformation. The interview guide included extra questions related to finances for 
Obtaining PCMH Organizational Buy-In

practice leaders and office administrators. Interviews were conducted by two teams of trained researchers.

Both teams, led by trained senior level graduate students and senior level associate professors, followed the same semi-structured interview schedule. In addition, one member of each of the two interviewer teams observed the other team's on-site interview sessions to identify and address any differences in interviewer style or delivery of the questions. Most interviews were conducted at the medical practice facility in private quarters during office hours. Participants were not compensated for their interview time. All procedures were reviewed and approved as ethical by the IRB.

Each participant was asked to describe his/her experiences with the rollout of the new patient-centered model, including its overall role, its level of adoption across the practice, its key leadership, accountability, communication processes, surprises, and lessons learned. Interviews ranged from 15-120 minutes; each was audio recorded and professionally transcribed.

\section{Data Analysis}

Interview transcripts were entered into NVivo, a qualitative analysis software package. Using constant comparison method, individual phrases relevant to the study purpose were identified, compared, and contrasted for the purpose of categorization, and then overarching themes that cut across the content categories were developed (Tracy, 2012). The process developed inductively.

This study implemented three phases of coding, with a prior codes including constructs from the OSMCI such as implementers'/stakeholders’ perceptions of change context, communication strategy choices and dimension, and interactions. In the primary phase, all interview files were transcribed, and all transcripts were then analyzed line-by-line to identify 
Obtaining PCMH Organizational Buy-In

broad codes reflecting stakeholder responses. In this process of open coding, a unit of meaning such as a word, sentence or paragraph containing related content and/or context were identified and labeled (Graneheim \& Lundman, 2004). Discrepancies in coding were resolved by group consensus. This primary phase of coding generated a descriptive codebook for this and the larger project including codes, code definitions, and illustrative examples.

To specifically address the research question in this study, during the secondary coding phase, the research team discussed the broad coding categories and identified those that would likely contain respondent information about strategies to promote buy-in. Additionally, a key term search was conducted on the entire dataset to search for the terms "buy-in," "commitment," “convince,” and “shared vision.”

Data within a number of the codes in the larger study provided valuable information pertinent to our research question about communication and organizational buy-in (e.g., buy-in and practice coaches, PCMH roll out). One member of the research team then commenced with focused coding, specifically analyzing meaningful units of data specific to organizational communication and buy-in.

In the tertiary phase, members of the team examined and discussed the relationships among the focused coding categories to identify conceptual linkages or themes across the categories of information. A theme, in this case, is conceptualized as a thread of underlying meaning that cut across codes and categories of codes at an interpretive level, serving as an expression of the latent content of the data (Graneheim \& Lundman, 2004). In the following section, we present the categories of strategies within each overarching theme.

\section{Findings}


Obtaining PCMH Organizational Buy-In

This study identified seven communicative strategies for obtaining medical practice buyin to medical home transformation. These strategies reflected three over-arching themes: (1) open, consistent communication that encourages active listening and feedback; (2) appropriate reinforcement techniques; and (3) a clearly identifiable PCMH “champion” or change implementer.

\section{Theme One: Effective Communication and Feedback}

\section{Consistent and collaborative meetings}

Respondents indicated that weekly staff meetings allowed for a greater emphasis on teamwork. Meetings were generally described as the setting for group discussions regarding important decisions, recognition of staff members, and performance reviews. Buy-in increased in cases where the atmosphere fostered staff communication on a weekly basis.

Collaborative aspects of team meetings also fostered greater communication. Respondents emphasized inclusive leadership, meaning that leadership promoted conversations that reserved time and space for reflection, encouraged different practice members speaking up, and promoted the sharing of ideas. Practice member input was an important requirement for buy-in. To illustrate, the following is an excerpt from a nurse:

...but otherwise, actually in the last two years, we had a remarkably stable staff, more stable than any time in the past. And I think that's partly because we've institutionalized all these meetings, and that we listen to staff and involve them more in discussions. It's like we try something - it's not like the doctors say, "We're going to do this. Now you go do it." It's like we say, "We have this idea about something. Let's work together to figure out the bugs and make it work." So it's that collaboration with the staff that actually involves them, and they're engaged. They contribute. They're a key part of this. 
Obtaining PCMH Organizational Buy-In

\section{Defining and justifying the PCMH model}

The "what," "how," and "why” question components of practice evolution were important to accomplish buy-in among practice members because answering these questions allowed staff members to learn about the benefits of model adoption. Providing basic information about what a PCMH is and how its process works served to educate practice members. Understanding why the model is needed for patient care and the options for how it might be carried out were central to education efforts, meaning that adequate time must also be allotted for the training of staff in new roles and procedures.

Respondents indicated that addressing the rationale - why - for needing organizational change was central to buy-in. When this issue was not addressed, results showed visible lag in buy-in at best and, in some cases, even a total lack of buy-in.

In many practices, organizational leaders successfully provided reasons for change; in others, instead of listing a variety of reasons, organizational leaders elicited reasons directly from practice personnel. A variety of reasons for organizational change emerged from the data, including (but not limited to) increased quality of patient care, financial incentives in becoming a medical home, and reduced medical costs for the office. Once practice personnel understood the potential benefits of transformation, a process of nurturing a shared vision often followed. After everyone demonstrated understanding and agreement on the "why" of change, a shared vision often followed that then guided organizational change decisions such as what kinds of changes were necessary and how personnel were to implement those changes.

\section{Promotion of different work, not harder work}

Respondents expressed the necessity for those in leadership roles to communicate to everyone in the practice from front desk staff to physicians that the model is not about adding 
Obtaining PCMH Organizational Buy-In

work responsibilities. To achieve the patient care and organizational process goals, the model does require flexibility in adjusting to different ways of working. Ground rules for communication were used among four practices in this study. The most important aspect of these team meetings was the emphasis on listening to other staff members in an effort to provide constructive feedback.

The patient-centered model required a great deal of change in some practices and less in others. For all practices, however, there was a practice of change — if not total transformation. Respondents were very clear that properly preparing staff and care personnel for the new ways of working is essential for buy-in. Respondents suggested that being mindful of the change process is essential, and that not minimizing the impact of change on a system is crucial, requiring a proactive, not reactive, approach. As one physician explained:

... one of the things I'm saying in the meeting is I really need staff to understand that this is not added responsibility. It's just a change in the way we practice, a lot of it. Because we have some issues with that, especially with the MAs [medical assistants]. They feel like they get a lot put on them...I just need to stress that becoming a medical home is not (about) doing more work. It's just going to be (that) you're going to do a different kind of work. You're going to do it differently.

\section{Theme Two: Reinforcement Techniques}

\section{Accentuation of positive efforts made by practice members}

This theme was not directly addressed by Lewis (2007) as being a core function of the implementation and stakeholder change model, but it can be assumed that positive reinforcement and repetition would most assuredly be occurring during a period of great transition and this 
Obtaining PCMH Organizational Buy-In

tactic is necessary for sufficient change in a behavior (Cacioppo \& Petty, 1989; McCullough \& Ostrom, 1974).

Respondents discussed the use of individual accolades and rewards systems that were put in place to congratulate and encourage those staff members excelling in the transformation process. Many practices mentioned the use of specific tactics in an effort to make a "big deal” when a practice member accomplished an important task toward an organizational goal. Leaders often attempted to accentuate positive efforts made by staff members, with some even having a rewards system in place to recognize those doing well. For example one office manager stated:

...I think making everybody feel like they are a part of it and every time an article comes out, or you know we have our NCQA plaque hanging in the lobby, so just those kinds of things, cheerleading, I think helps a lot. One of the things we did was after the "lunch and learns" for the MAs, we gave them WaWa gift cards, gifts for lunch, here’s “thanks” for participating in this, just things like that.

\section{A public display of outcomes can help to promote positive competition among} organizational members

These practices often implemented and encouraged public reporting of individual provider successes and challenges in critical areas such as patient compliance and chronic care management statistics. National accrediting bodies such as the NCQA suggest this very kind of benchmarking. Since PCMH certification depends on accomplishing national benchmarks and thresholds for care, publicly displaying individual care provider outcomes served to establish a public accountability within practices.

Additionally, many practices initiated a (most of the time) friendly sense of competition with nearby care organizations by posting the reports of other organizations and encouraging 
Obtaining PCMH Organizational Buy-In

personnel to exceed the standards set by other organizations (consistent with an observable behavior as described in stakeholder theory) (Freeman, 1984). Practices displayed results via charts, rates, and other reporting using public bulletin boards, storyboards, or visual monthly reports. This was used as a way to motivate staff members, with the belief that "getting the competitive juices flowing” would increase staff awareness regarding performance, while also promoting positive changes. One practice leader described their experience with this technique: We actually had a big bulletin board in the lobby, and we actually shared some of our outcomes with the patients. We've had to make storyboards for our presentations at the learning collaborative. And these had our numbers on them, so we were actually publically sharing the data where we come from.

\section{Theme Three: A change implementer (known as the PCMH champion or leader) is crucial}

1. Frequent face-to-face communication between leaders and personnel

Respondents expressed that having a PCMH champion to interact with increased buy-in. Champions/change implementers may certainly be physicians, but may also be any other influential members of a health care organization who are knowledgeable about the medical home and its principles, those who may be called upon to lead the decision to become a medical home, and the planning for its implementation.

This need fits well with stakeholder theory's consideration of the individual who serves as a change implementer (Lewis, 2007) and previous patient-centered research that has expressed a strong need for such an individual in the adoption process while still maintaining a culture of teamwork and collaboration (Dorrance et al., 2013; Gurewich, Cabral, \& Sefton, 2016). These champions (also known as implementers) serve as motivational coaches, guiding practice personnel throughout the process, leading by example and were always successful 
Obtaining PCMH Organizational Buy-In

communicators. Research has explicated the instrumental role of the change implementer in stakeholder theory, with an instrumental approach recommended for the success of the organization. Stakeholders can be the difference between success being assisted or impeded, which emphasizes the need for their interests, opinions, and concerns; however, the change implementer is the one responsible for managing these views in the most appropriate way for the organization.

Successful PCMH implementers encouraged face-to-face, truly interpersonal, communication amongst staff members. New health information technologies were frequently developed during the rollout of the initiative, making it easier for practice members to communicate electronically. Champions also facilitated conversations among care personnel and staff that promoted organizational and care changes within the medical practice, with the intention of encouraging each member to develop his/her own short-term goals to accomplish the larger objective of collectively running a successful medical home.

When a champion guided personnel to identify their own objectives and capabilities for change, the goal of transformation was perceived as more realistic. Through the use of face-toface communication during staff meetings, champions guided practice members to set realistic goals for change and to think of ways to overcome any difficulties they might envision, all while guiding and informing along the change process to refine change efforts. One champion stated, “You come up with a plan, try it, and if it doesn’t work, we'll figure out a way [together] to fix it," and another pointed out that "the staff and everyone need to see the need [for change] for themselves and they all need to participate in the process. They ARE the process of change.”

\section{Promoting transition above transformation}


Obtaining PCMH Organizational Buy-In

Respondents pointed out the importance for staff leaders to communicate that merely introducing the model and its principles will not initiate immediate transformation. Practice members discussed that practice leaders were viewed as helpful when they communicated the transformation transparently as an involved process and also articulated the changes necessary in a realistic way. Electronic medical record (EMR) implementation, for example, was reported as a long and challenging step, but when guided by PCMH principles toward positive reward, most participants agreed that "slow and steady wins the race."

Participants recommended that champions emphasize realistically what the scope of “transformation” truly entails. As one respondent stated, “In principle we have agreement, but in practice it is a bit more difficult.” In order to get from point A to point B, practice members will be required to take many steps along the way.

The results of this study suggest that there are a series of "baby steps" that can be used in order to achieve increased levels of buy-in. There clearly seems to be a recommendation to move away from the rhetoric of "transformation" to one of "transitioning."

\section{Discussion}

This study was guided by stakeholder theory to investigate messages promoting organizational change in a medical practice setting; specifically, medical practices seeking formal status as a patient-centered medical home. In an effort to further expand definitions and understanding of patient centeredness, this research aggregates the first-hand experiences of providers, as suggested by Liberati et al. (2015), identifying structural and procedural approaches that can help achieve a greater patient centered approach.

\section{Major Themes}


Obtaining PCMH Organizational Buy-In

This study identified seven specific communicative strategies for obtaining medical practice buy-in to the PCMH transformation. These strategies reflected three over-arching themes: (1) effective communication and feedback; (2) appropriate reinforcement techniques can help; and (3) a clearly identifiable "champion" or "team leader" needs to be in place to encourage and facilitate successful organizational change.

Themes one and three proved to be consistent with Lewis' model (2007), whereas theme two could be an area of future research for possible adaptation of the model. Coordination of these recommendations alongside Lewis’ model of organizational change implementation (2007) can be seen in Table I, showing that this model may prove helpful for future health care organization research focusing on practice transformation.

\section{Links with Theory}

Viewing the results of this study through the lens of stakeholder theory provides added insight into the reasons why certain messages were perceived as most effective in securing buyin from practice members. Stakeholder theory argues that successful change management is more likely to occur if key communicative techniques are present (Phillips, 2005; Rosch, 2002) and definable aims and goals are communicated to organization members (Freeman, 1984). According to stakeholder theory, effective communicative strategies serving as an integral part in explaining: reasons for the change, benefits of implementation (what is in it for patients and practice members), and the details of the change (offering step-by-step information on the processes involved) (Anderson \& Anderson, 2001). The data in this study support these theoretical assumptions of stakeholder theory, including: emphases on change implementer response to stakeholder challenges during times of transition, a need for defining and conceptualizing one’s own organization, and incorporating various participants into decision 
Obtaining PCMH Organizational Buy-In

making processes. This research helps to extend stakeholder theory by showing how it can be helpful in the context of health care. Interview participants in this study reported needing to know why changes were being implemented, leading to a culture of active participation from various stakeholders. It is important to note, however, that the organization should develop clear stakeholder prioritizations before incentive systems are designed. One means of doing so involves the change implementer auditing the expectations of stakeholders and comparing this list with the organization's core values and broader societal standards (Freeman, 1984).

As stated by Solberg (2007), transformation in a medical practice involves incremental changes that are in place to eventually alter the fundamental culture of the organization. In this sense, transitioning to a PCMH involves a series of planned steps that take time to implement, yet if communicated to practice members successfully, can aid in moving from a hierarchical (top-down) structure in the medical practice toward more self-directing teams (Solberg, 2007). This research confirms the need for systematic, incremental change, while also extending stakeholder theory to accommodate the field of health care. The results of this study show how health care employees act during the period of transition to a medical home, while presenting a greater need for practice members to reflect upon their own words and actions, consistent with stakeholder theory and OSMCI.

\section{Role of the Practice Leader}

It is important to note that while the results of the current study suggest a collaborative approach to decision-making and planning may be perceived as most effective, clear messages from a strong "transformational leader” are still necessary for the most successful changebass . Interdisciplinary teams offer various benefits, including different types of perspectives and points of view that provide greater access to solutions made within the framework of a team 
Obtaining PCMH Organizational Buy-In

(Johnson, 2013). In addition, clear goals, guidelines for practice, and roles and responsibilities are paramount. Practice members ought to able to identify: intrinsic motivations for making organizational changes, opportunities that may arise if change occurs (i.e., making more time for patient appointments), expectations if change occurs (i.e., how to manage new health technologies), and their willingness to make changes. Stakeholder theory posits that in order for change management to function as an effective tool, the lead implementer must do more than summarize organizational practices; rather, the implementer should view his or her self as enabling the organization to achieve its own objectives (Atkinson, Waterhouse, \& Wells, 1997).

\section{Role of Practice Members and Facilitation of the PCMH Change}

The results of this study show that practice members need a change implementer to first perceive and communicate the current practice context and its vision for change, consistent with stakeholder theory (Freeman, 1984). The members need to hear from the change implementer why the practice is evolving into a medical home, what the evolution means for the practice as a whole, and how the practice can best evolve via open and consistent communication.

As is also seen in transformational leadership literature, practice members ought to be encouraged to work as a unified team while also creating their own individual short-term goals (Bass, 1985). The data correspond with the theoretical framework of this study, in that they show that obtaining buy-in for practices proves most successful when a clear champion/leader is present. Stakeholder theory and Lewis' model of change implementation call for a clear “change implementer” to be present in order for the change to have a positive impact (Lewis \& Siebold, 1993; Lewis \& Siebold, 1998; Lewis, 2007).

The data suggest that for champions to be perceived as successful in motivating buy-in to organizational change, they must be seen as providing guidance over directing others; this is 
Obtaining PCMH Organizational Buy-In

consistent with the findings of Hendy and Barlow (2012), wherein organizational champions are found to be highly effective during first stages of new behavior adoption. Instead of dictating change or directing personnel toward change, these implementers served as guides or coaches, activating the practice members own intrinsic reasons and motivations for change.

According to this data, buy-in may be better understood when applying Lewis’ model of change implementation (2007) at an organizational level, as the model addresses specific facets of communication (e.g. context, strategy, response, observations) rather than viewing the change process from a macro level. Additionally, as is demonstrated in concurrent research findings, consistent training opportunities associated with practice changes are necessary to ensure that providers understand not only what they need to be doing differently, but also why it is important to be doing so (Najib Balbale, Turcios, \& LaVela, 2015).

The findings of this study offer a concrete list of perceived communicative strategies for facilitating greater medical practice buy-in to the PCMH model for primary care. The interpretation of these findings can also be extrapolated to an existing model of practice: one of transformational leadership that is applied at an organizational level that encourages team-based participation and effort.

Our findings of open communication, specifically techniques promoting listening and feedback, guiding rather than directing, activating intrinsic motivations and reasons for change, addressing ambivalence, emphasizing different options for behavior, positive reinforcement for small successes, and ongoing coaching and guidance are all consistent with the OSMCI.

Still, limitations to this research exist. This study focused on a particular geographical area, which may account for cultural differences in process understanding by practice members. 
Obtaining PCMH Organizational Buy-In

Additionally, this study did not interview patients to gauge their interpretation of the experience, which is arguably the most important aspect to assessing health care quality and performance.

The results of this study suggest that transformational leadership principles relate to the processes of buy-in when medical practices adopt the patient-centered model. The importance of organizational behavior dates back to the Hawthorne studies, which demonstrated that informal, internal groupings might have profound effects on practice performance (Kilduff \& Tsai, 2003). It is important to note that transformational leadership is not coercion or simply getting others to do what the leader wants them do. Rather, it is about using an evocative method to elicit and reinforce motivation and readiness to change specific behaviors, while also encouraging a discussion linking these changes to important personal characteristics (Levensky, Forcehimes, O’Donohue, \& Beitz, 2007).

\section{Recommended Strategies for Successful Transformation}

Expressions of empathy, developments, and subsequent discussions regarding challenges and discrepancies, continuing with transformation while addressing resistance, and supporting self-efficacy are all indicators of successful organizational changeThe results of this study suggest that these techniques, while commonly used among health care providers and patients, could also be used for effective organizational change, specifically in the context of PCMH model implementation. Below, each principle is briefly described, followed by a visual representation of how these principles were reflected in the data for this study pertaining to obtaining buy-in for organizational change (see Tables I and II):

- Expressing empathy involves an individual's understanding regarding someone else’s experience with change. 
- Developing a discrepancy is when an individual uses available information to enhance another's awareness of inconsistencies between behaviors and results to motivate change.

- Continuing with transformation amidst resistance means that individuals become the primary source for solutions to problems that they are experiencing. This is a way of directly involving individuals in the process for remedying a situation.

- Support for self-efficacy involves an expression in the belief for possibility of change, with an emphasis being placed on one’s ability to choose and carry out change.

Additionally, the three themes found in this study can offer a series of best practices for successful communication among health care providers in order to obtain greater buy-in, based on the principles of organizational development theory. In order to obtain buy-in, health care providers would be served by: encouraging open, consistent communication that allows for feedback, using appropriate reinforcements or rewards to encourage change, and having one knowledgeable champion in place to answer questions and lead by example in terms of medical home evolution. Specifically, the OSMCI could be a helpful tool for change implementers to consider during the change process - by addressing each specific area of the model, perhaps challenges can be better understood and solutions more appropriately executed.

\section{Conclusion}

Rhetorical strategy for a successful PCMH transition may also be an important factor in obtaining buy-in. This study suggests that open and clear communication is extremely important among health care providers, meaning that being truthful about the process of switching to a medical home and its challenges is crucial. Health care providers, including medical home champions, should avoid referring to the transition from a traditional medical practice to a PCMH as a "transformation," as this language is misleading. Using the rhetoric of 
Obtaining PCMH Organizational Buy-In

"transformation" implies a dramatic and thorough change, which is simply not the case. Future research and health care providers themselves need to refer to this as more of an "evolutionary process.”

Addressing the adoption of PCMH principles in the language of evolution implies that gradual - yet significant - changes will take place. Informing practice members from the beginning that this truly is a process, full of baby steps and incremental changes, is necessary and important in order to keep lines of communication honest and open.

Designated leaders should take a more managerial approach with staff members, communicating with them in ways similar to motivating patients for behavioral change. This involves addressing more than an organization's readiness for change, but also identifying an organization's resources, climate, flexibility, and attitude. Leaders will need to strategically use reflective listening techniques, acknowledge both sides of ambivalence regarding medical home adoption and execution, and affirm confidence in the ability to successfully change because of the importance of the evolution. Additionally, it will be necessary for the change leader to evaluate the capacity and willingness of various stakeholders during processes of change, with actions sortable into 3 categories: observed behavior, cooperative potential, and/or competitive threat (Freeman, 1984). By further understanding the reactions of stakeholders, the change implementer can develop more appropriate responses for increasing organizational success.

Additionally, honesty about the process of these changes will encourage further problemsolving among practice members and providers if and when challenges do arise, thereby further encouraging the team-based care that the medical home promotes (Kirk, 2007).

Furthermore, the three themes found in this study can be used to develop a series of steps to be taken that can facilitate successful patient-centered model adoption and practice change 
overall (see Table II). Via analyses of stakeholder theory in the health care delivery system, future research can better investigate managerial direction with greater empirical tractability, providing clearer implications.

Overall, this study suggests that addressing basic communicative principles among practice team members before, during, and after rollout can increase buy-in when done in an effective manner alongside principles of stakeholder theory. Medical practice members must develop better communicative strategies among providers when undergoing the evolution in order to best benefit from its outcomes.

Like the rollout evolution, communicative shifting is an ongoing process that can be nurtured through consistent, open, and positive communicative strategies. The outcomes will be worth the work: better communication amongst staff members will inevitably lead to clearer communication between patients and their providers.

This study found that consideration of stakeholder theory principles and models can lead to greater understanding of what it takes to achieve health care organizational buy-in, ultimately aiming to achieve even greater success with the PCMH model. 
Obtaining PCMH Organizational Buy-In

\section{References}

American Academy of Family Physicians, American Academy of Pediatrics, American College of Physicians, \& American Osteopathic Association. (2009, April). Joint statement on nurse practitioners in patient-centered medical home demonstration projects. Retrieved from http://www.aafp.org/online/en/home/publications/news/news-now/ Opinion/20090429opin-nps-med-homes.html

American College of Physicians. (2014). Costs, benefits \& incentives: The three-part payment model. Retrieved from http://www.acponline.org/running_practice/delivery_and_payment_models/pcmh/cost_b enefit/index.html

Anderson, D., \& Anderson, L. A. (2001). Beyond change management: Advanced strategies for today’s transformational leaders. San Francisco, CA: Jossey-Bass/Pfeiffer.

Applequist, J. (2013). Constructions of the patient as consumer in the patient-centered medical home. Journal of Communications Media Studies, 5(1), 44-58.

Atkinson, A. A., Waterhouse, J. H., \& Wells, R. B. (1997). A stakeholder approach to strategic performance measurement. Sloan Management Review, 38(3), 25-37. 
Obtaining PCMH Organizational Buy-In

Aysola, J., Werner, R. M., Keddem, S., SoRelle, R., \& Shea, J. (2015). Asking the patient about patient-centered medical homes: A qualitative analysis. Journal of General Internal Medicine, 30(10), p. 1461-1467. doi: 10.1007/s11606-015-3312-8

Bass, B. M. (1985). Leadership and performance beyond expectation. New York: Free Press. Beaulieu-Volk, D. (2015). PCMH playbook: 7 steps to plan today for a value-based payment future. Medical Economics, 92(17), 18-28.

Berenson, R. A. \& Horvath, J. (2003). Confronting the barriers to chronic care management in Medicare. Health Affairs, 22(2), 11.

Bleser, W. K., Miller-Day, M., Naughton, D., Bricker, P. L., Cronholm, P. F., \& Gabbay, R. A. (2014). Strategies for achieving whole-practice engagement and buy-in to the patientcentered medical home. The Annals of Family Medicine, 12(1), 37-45. doi: 10.1370/afm.1564

Cacioppo, J. T., \& Petty, R. E. (1989). Effects of message repetition on argument processing, recall, and persuasion. Basic \& Applied Social Psychology, 10(1), 3-12.

Crocker Houde, S., Devereaux Melillo, K., \& Holmes, R. (2012). The patient-centered medical home. Journal of Gerontological Nursing, 38(3), 12-16. doi: 10.3928/0098913420120207-06

Donaldson, T. (1999). Making stakeholder theory whole. Academy of Management Review, 24(2), 237-241.

Dorrance, K.A., Ramchandani, S., LaRochelle, J., Mael, F., Lynch, S., \& Grundy, P. (2013). Protecting the culture of a patient-centered medical home. Military Medicine, 178(2), 153-158. doi: 10.7205/MILMED-D-12-00146 
Obtaining PCMH Organizational Buy-In

Elhauge, E. (2010). The fragmentation of U.S. health care: Causes and solutions. New York, NY: Oxford University Press.

Elms, H., Berman, S., \& Wicks, A. C. (2002). Ethics and incentives: An evaluation and development of stakeholder theory in the health care industry. Business Ethics Quarterly, 12(4), 413-432. doi: 10.2307/3857993

Epperly, T. (2011). The patient-centered medical home in the USA. Journal of Evaluation in Clinical Practice, 17(2), 373-375. doi: 10.1111/j.1365-2753.2010.01607.x

Freeman, R. E. (1984). Strategic management: A stakeholder approach. Boston: Pitman.

Freeman, R. E. (2002). Stakeholder theory of the modern corporation. In T. Donaldson and P. Wehane (eds.), Ethical issues in business: a philosophical approach ( $8^{\text {th }}$ ed) (pp. 38-48). Englewood Cliffs, NJ: Prentice Hall.

Freeman, R. E., \& Philips, R. (2002). Stakeholder theory: A libertarian defense. Business Ethics Quarterly, 3(12), 331-350. doi: 10/2307/3858020

Garcia, T. J., Harrison, T. C., \& Goodwin, J. S. (2016). Nursing home stakeholder views of resident involvement in medical care decisions. Qualitative Health Research, 26(5), 712728. doi: $10.1177 / 1049732315573206$

Garside, P. (1998). Organizational context for quality: Lessons from the fields of organizational development and change management. Quality in Health Care, 7(DEC).

Graneheim, U. H., \& Lundman, B. (2004). Qualitative content analysis in nursing research: Concepts, procedures and measures to achieve trustworthiness. Nurse Education Today, 24, 105-112. doi: 10.1016/j.nedt.2003.10.001 
Obtaining PCMH Organizational Buy-In

Grumbach, K., \& Bodenheimer, T. (2004). Can health care teams improve primary care practice?. Journal of the American Medical Association, 291, 1246-1251. doi: 10.1001/jama.291.10.1246

Gurewich, D., Cabral, L., \& Sefton, L. (2016). Patient-centered medical home adoption: Lessons learned and implications for health care system reform. Journal of Ambulatory Care Management, 39(3), 264-271. doi: 10.1097/JAC.0000000000000118

Hendy, J., \& Barlow, J. (2012). The role of the organizational champion in achieving health system change. Social Science \& Medicine, 74, 348-355. doi: 10.1016/j.socscimed.2011.02.009

Johnson, J. D. (2013). Dosage: A guiding principle for health communicators. (p. 36). Lanham, MD: Rowman \& Littlefield Publishing Group.

Joint principles of the patient-centered medical home. (2007, March 1). Retrieved from http://www.acponline.org/running_practice/pcmh/demonstrations/jointprinc_05_17.pdf

Jones, T. M., \& Wicks, A. C. (1999). Convergent stakeholder theory. Academy of Management Review, 24, 206-221.

Kajamaa, A., \& Hilli, A. (2013). Clients’ initiatives and caregivers’ responses in the organizational dynamics of care delivery. Qualitative Health Research, 24(1), 18-32. doi: $10.1177 / 1049732313514138$

Keeley, R. D., West, D. R., Tutt, B., \& Nutting, P. A. (2014). A qualitative comparison of primary care clinicians’ and their patients’ perspectives on achieving depression care: Implications for improving outcomes. BMC Family Practice, 15(1), 13-36. doi: $10.1186 / 1471-2296-15-13$ 
Obtaining PCMH Organizational Buy-In

Kilduff, M., \& Tsai, W. (2003). Social networks and organizations. Thousand Oaks, CA: Sage.

Kirk, L. M. (2007). The patient-centered medical home care model: Implications for physician assistant education. Journal of Physician Assistant Education, 18(4), 7-8.

Korda, H., \& Eldridge, G. N. (2011). ACOs, PCMHs, and health care reform: Nursing's next frontier? Policy, Politics, \& Nursing Practice, 12(2), 100-103. doi:

$10.1177 / 1527154411416370$

Kralewski, J., Zink, T., Dowd, B., \& Tong, J. (2016). A tale of two family practice clinics: How they adopted patient-centered care, but couldn’t sustain it. Physician Leadership Journal, 3(2), 12-20.

Kuzel, A. J., \& Skoch, E. M. (2009). Achieving a patient-centered medical home as determined by the NCQA - at what cost, and to what purpose? Annals of Family Medicine, 7, 85-86. doi: 10.1370/afm.956

Levensky, E. R., Forcehimes, A., O'Donohue, W. T., \& Beitz, K. (2007). Motivational interviewing: An evidence-based approach to counseling helps patients follow treatment recommendations. American Journal of Nursing, 107(10), 50-58.

Lewis, L. K., \& Siebold, D. R. (1993). Innovation modification during intraorganizational adoption. Academy of Management Review, 18, 322-354. doi:

10.5465/AMR.1993.3997518

Lewis, L, K., \& Siebold, D. R. (1998). Reconceptualizing organizational change implementation as a communication problem: A review of literature and research agenda.

Communication Yearbook, 21, 92-151. 
Obtaining PCMH Organizational Buy-In

Lewis, L. K. (2007). An organizational stakeholder model of change implementation communication. Communication Theory, 17, 176-204. doi: 10.111//j.14682885.2007.00291.x

Lewis, L, K. (2011). Organizational change: Creating change through strategic communication. Malden, MA: Wiley-Blackwell.

Liberati, E. G., Gorli, M., Moja, L., Galuppo, L., Ripamonti, S., \& Scaratti, G. (2015). Exploring the practice of patient centered care: The role of ethnography and reflexivity. Social Science \& Medicine, 133, 45-52. doi: 10.1016/j.socscimed.2015.03.050

Maeng, D. D., Graf, T. R., Davis, D. E., Tomcavage, J., \& Bloom Jr., F. J. (2011). Can a patientcentered medical home lead to better patient outcomes? The quality implications of Geisinger's ProvenHealth navigator . American Journal of Medical Quality, 27(3), 210216. doi: $10.1177 / 1062860611417421$

McCullough, J. L, \& Ostrom, T. M. (1974). Repetition of highly similar messages and attitude change. Journal of Applied Psychology, 59(3), 395-397.

Morden, A., Nio Ong, B., Brooks, L., Jinks, C., Porcheret, M., Edwards, J. J., \& Dziedzic, K. S. (2015). Introducing evidence through research "push”: Using theory and qualitative methods. Qualitative Health Research, 25(11), 1560-1575. doi:

$10.1177 / 1049732315570120$

Najib Balbale, S., Turcios, S., \& LaVela, S. L. (2015). Health care employee perceptions of patient-centered care. Qualitative Health Research, 25(3), 417-425. doi:

$10.1177 / 1049732314553011$ 
Obtaining PCMH Organizational Buy-In

Nutting, P. A., Crabtree, B. F., Miller, W. L., Stewart, E. E., Stange, K. C., \& Jaén, C. R. (2010). Journey to the patient-centered medical home: A qualitative analysis of the experiences of practices in the national demonstration project. Annals of Family Medicine, 8(1), 545-556. doi: 10.1370/afm.1075

O’Malley, A. S., Gourevitch, R., Draper, K., Bond, A., \& Tirodkar, M. A. (2015). Overcoming challenges to teamwork in patient-centered medical homes: A qualitative study. Journal of General Internal Medicine, 30(2), 183-192. doi: 10.1007/s11606-014-3065-9

Phillips, J. R. (1983). Enhancing the effectiveness of organizational change management. Human Resource Management, 22(1/2), 183-199. doi: 10.1002/hrm.3930220125

Phillips, R., Freeman, R. E., \& Wicks, A. C. (2003). What stakeholder theory is not. Business Ethics Quarterly, 1, 479-502.

Reid, R. J. (2013). Spreading a medical home redesign: Effects on emergency department use and hospital admissions. Annals of Family Medicine, 11(Suppl. 1), S19-S26. doi: 10.1370/afm.1476

Rittenhouse, D. R., Shortell, S. M., \& Fisher, E. (2009). Primary care and accountable care: Two essential elements of delivery-system reform. New England Journal of Medicine, 361(24), 2301-2303. doi: 10.1056/NEJMp0909327

Rosch, E. (2002). Lewin's field theory as situated action in organizational change. Organization Development Journal, 20(2), 8-13.

Rothwell, W. J., Stavros, J. M., Sullivan, R. L., \& Sullivan, A. (2010). Practicing organization development: A guide for leading change. (3rd ed.). San Francisco, CA: Pfeiffer. 
Obtaining PCMH Organizational Buy-In

Salmela, S., Eriksson, K., \& Fagerström, L. (2013). Nurse leaders’ perceptions of an approaching organizational change. Qualitative Health Research, 23(5), 689-699. doi:

$10.1177 / 1049732313481501$

Solberg, L. I. (2007). Improving medical practice: A conceptual framework. Annals of Family Medicine, 5(3), 251-256. doi: 10.1370/afm.666

Stieb, J. A. (2009). Assessing Freeman's stakeholder theory. Journal of Business Ethics, 87(3), 401-414.

Tai-Seale, M., Dohan, D., Chung, S., Hung, D., Frosch, D., Wilson, C., McCuistion, M., \& Kohli, N. (2012). Transforming primary care in 3 NCQA-certified PCMHs. Clinical Medicine \& Research, 10(3), 171. doi: 10.3121/cmr.2012.1100.ca7-05

Tracy, S. J. (2012).Qualitative research methods: Collecting evidence, crafting analysis, communicating impact. Oxford: Wiley-Blackwell.

Tuepker, A., Kansagara, D., Skaperdas, E., Nicolaidis, C., Joos, S., Alperin, M., \& Hickam, D. (2014). ‘We’ve not even gotten close to what we want to do’: A qualitative study of early patient-centered medical home implementation. Journal of General Internal Medicine, 29(2), 614-622. doi: 10.1007/s11606-013-2690-z

Wendell, F. L., Bell, C. H., \& Zawacki, R. A. (1978). Organizational development: theory, practice, and research. (p. 5). Dallas, TX: Texas Business Publications, Inc.

Wise, C. G., Alexander, J. A., Green, L. A., Cohen, G. R., \& Koster, C.R. (2011). Journey toward a patient-centered medical home: Readiness for change in primary care practices. Milbank Quarterly, 89(3), 399-424. doi: 10.1111/j.1468-0009.2011.00634.x

Zarbock, S. (2011). There's no place like the patient-centered medical home. Journal of the American Academy of Physician Assistants, 24(4), 20. 
Figure 1

\section{A Model of Implementation Communication Strategy Selection, Stakeholder Concerns, Assessments, Interactions, and Outcomes (OSMCI)}
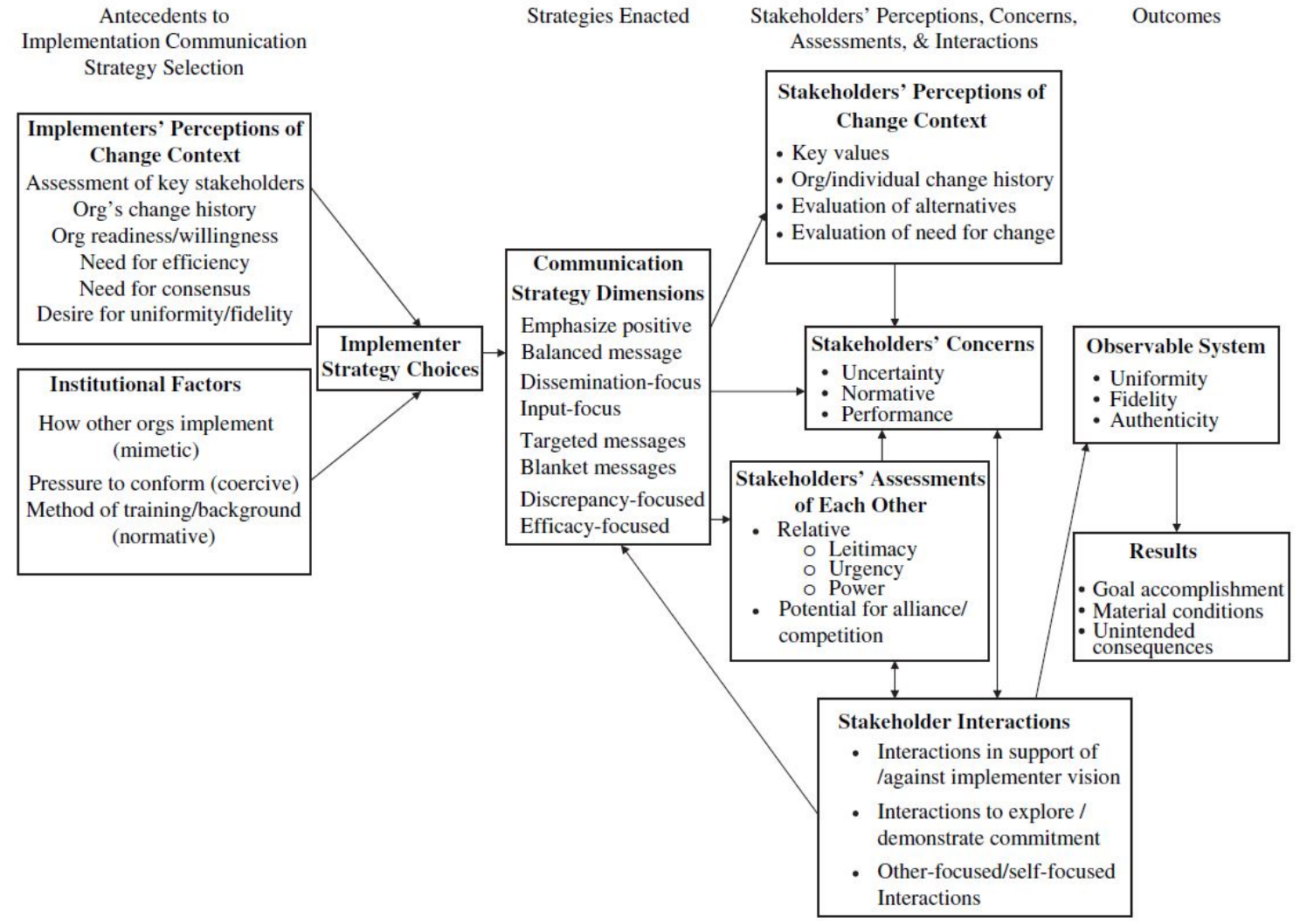
Obtaining PCMH Organizational Buy-In

Source: Lewis, L. K. (2007). An organizational stakeholder model of change implementation communication. Communication Theory, 17, 176-204. doi: 10.111//j.14682885.2007.00291.x

\section{Table I}

Effective Strategies Present in Model of Implementation Strategy and Present in Current Study

\section{Stage of Model of}

Theme

Open, consistent

communication with

listening \& feedback

loops

Use of appropriate

reinforcement

techniques in the

medical practice

(Lewis, 2007)

performance
Implementation Strategy

Stakeholders’ perceptions,

concerns, assessments, and

interactions; Stakeholders’

concerns of uncertainty and

Enacting communication strategy dimensions (emphasis

of positive aspects in

Example(s) in Association with PCMH Roll-Out

Addressing concerns during

weekly meetings, using meetings

as an opportunity to problem-

solve for the medical practice 
Obtaining PCMH Organizational Buy-In

messaging, targeted messages, storyboards, bulletin boards to and efficacy-focused language) show progress

Having a PCMH Implementers’ perceptions of Leading by example, motivating “champion” or leader change context; Observation of other practice members, in place to encourage system, interactions, and results addresses challenges as a practice successful evolution as they present 
Table II

\section{Communicative Strategies Useful in Facilitating PCMH Evolution}

\section{“Baby Steps” for PCMH}

\section{Evolution}

How to Increase Buy-In via Specific Messages Reported

Communicative Strategies that Increased Buy-In
1. Introduce one new

learning curve to

practice members at a

time.

2. Master that learning

curve through a

learning collaborative

or training (e.g.: open

scheduling).

3. Convince other

practice members to

get on
Encourage constant, open-

ended communication (e.g.:

"We can do this."
Allow staff meeting agendas to be negotiated.

Creatively develop

incremental strategies for change.
“We're figuring it out together.”
“Try it.” 
board/encourage the

change.

Encourage a high level of

4. Participate in ongoing autonomy among practice training and retraining. members to creatively address change issues.

Have individuals with

5. Share information about changes with patients.

authority in place that can

facilitate, reward, and

encourage.

Allow practice goals to be negotiated, listen to all

6. Evaluate if it is working for you (the health care providers), involved in developing as well as for the patients.

practice members being strategies for successful change, and practice
“We can fix it if it doesn’t work."

“Show by example.”

“It's not about us working harder, but about us working opinions and ideas, with all as a team.” members must provide informational, instructional, and emotional support
"We can put some energy into this.”
"What can we gain by these changes?” 